Indiana Working Papers in South Asian Languages and Cultures

\title{
A VOWEL SPACE COMPARISON OF TLAWNGRANG ZOPHEI AND LAWNGTLANG ZOPHEI
}

\author{
July, 2019 \\ Samson A. Lotven, Kelly H. Berkson ${ }^{1}$ \\ ${ }^{1}$ Indiana University Department of Linguistics
}

\begin{abstract}
Zophei is an undescribed Tibeto-Burman language within the Kuki-Chin family. Originally spoken in the Chin Hills of Western Myanmar, approximately 4,000 Zophei-speaking refugees now live in Central Indiana. No previous research on Zophei exists. The speakers located in Indiana who identify as ethnically Zophei hail from 14 distinct villages, and it is not yet known how many dialects or languages are represented. As part of a larger effort to kick-start a research program on Zophei, the current study presents vowel spaces for two speakers, one from Tlawngrang and one from Lawngtlang. Differences with regard to the number and distribution of high vowels and diphthongs indicate that these two areas speak different varieties with markedly different phonologies. For example, where one speaker has an /ui/ diphthong the other speaker consistently has the front rounded monophthong $/ y /$. This research contributes to our ultimate goal, which is to determine the dialectal make-up of Zophei and to develop a description of the language or languages spoken by the ethnic Zophei population in Indiana.
\end{abstract}

Key Terms-Zophei, Zyphe, vowel shift, monophthongization, Kuki-Chin

\section{INTRODUCTION}

Zophei (or Zyphe ISO 639-3 ZYP) refers to the undescribed language spoken by the Zophei ethnic group of Myanmar. This paper presents the first description of Zophei by offering a comparison of the vowel systems of two speakers. Both are from the Lower Zophei area, one from the village of Tlawngrang and one from the village of Lawngtlang. The goals of this research are to provide foundational empirical data and to propose and analysis of the diachronic changes that likely led to differences in the two vowel systems. This analysis suggests that the Tlawngrang dialect is more conservative than the Lawngtlang dialect and that two chain shifts, one involving front vowels and one involving back vowels, can account for many of the differences between these speakers' vowel systems. In section 2, we present background on Zophei. Section 3 offers an overview of the methodology used in this study. Section 4 contains a comparison of the two speakers' vowel spaces focusing on long and short monophthongs as well as diphthongs. Section 5 proposes the two aforementioned chain shifts and section 6 concludes the paper.

\section{BACKGROUND}

Zophei belongs to the Maraic cluster of Kuki-Chin, a group of Tibeto-Burman languages spoken in Chin State in Myanmar and Mizoram State in India (VanBik 2009). A 1994 Ethnologue estimate reported 17,000 Zophei speakers in Chin State and 20,000 worldwide (Simons \& Fennig 2018). 


\section{Indiana Working Papers in South Asian Languages and Cultures}

Since that time, a large number of Chin refugees have left Myanmar and settled in the US, most prominently in Indiana where an estimated 4,000 ethnic Zophei currently live (Vahnie, p.c.). The Zophei population in Myanmar is centralized around a cluster of villages in southern Thantlang Township. Figure 1 shows an incomplete map of villages in the region with all the Zophei villages provided highlighted in grey with boxes around the village names. Arrows show the language spoken these villages.

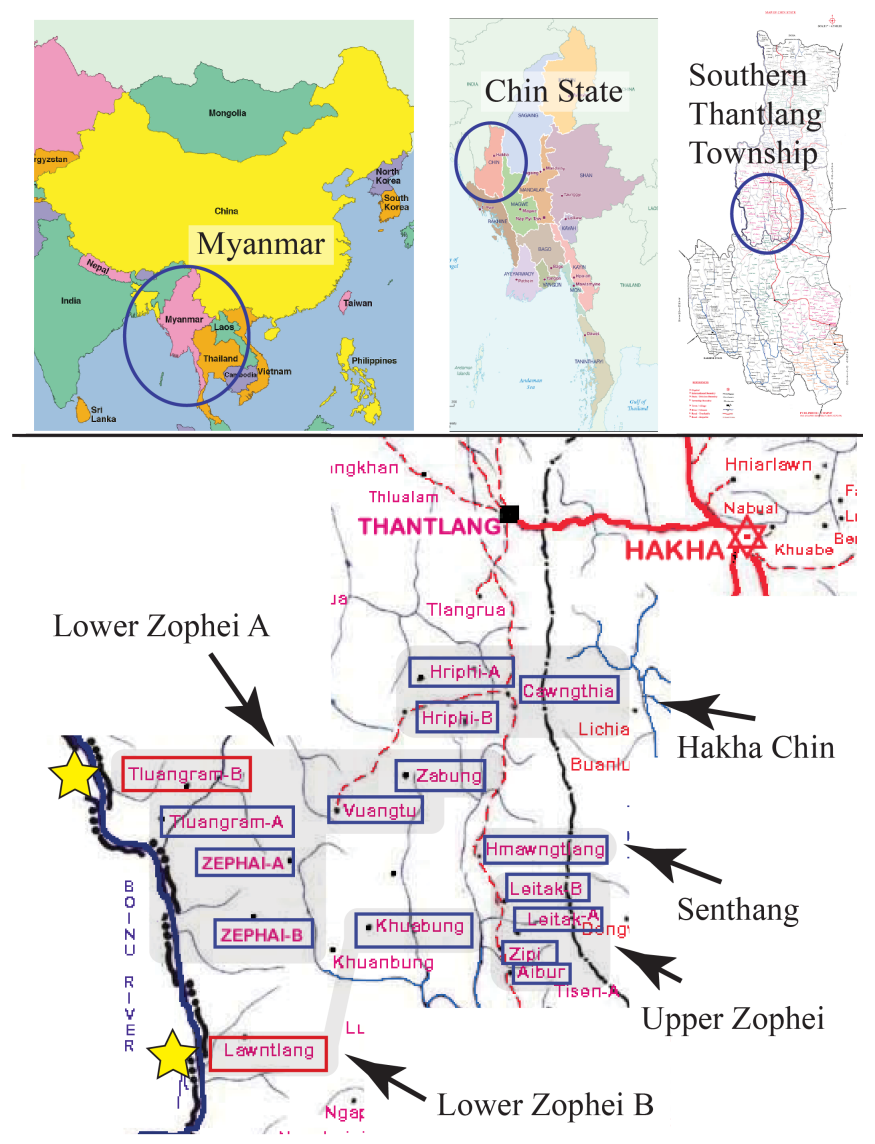

Figure 1. Map of languages spoken in ethnic Zophei villages. ${ }^{1}$

Not all ethnic Zophei people speak Zophei. In northern villages such as Hriphi and Cawngthia people mainly speak Hakha Chin (the language of wider communication in much of Chin state), and in some eastern villages such as Hmawngtlang people mainly speak Senthang (another Maraic language). According to Zophei community members, Zophei can be divided between Upper Zophei in the southeast and Lower Zophei in the west. Community members also describe Lower Zophei as further subdivided into two dialects, here preliminarily called Lower Zophei A (in the northwest) and Lower Zophei B (in the southwest). The villages of the two study participants (Tlawngrang and Lawngtlang) are indicated with yellow stars and offer a first look into the Lower Zophei A and B dialects, respectively.

${ }^{1}$ Figure 1 map sources:

World Map: https://wallscover.com/asia.html

Burma Map: http://asiapacific.anu.edu.au/mapsonline/system/files_force/maps/bitmap/standard/2016/01/13058b_Burma_states.png?download $=1$

Chin State Map: Chin Baptist Mission Youth Fellowship, Pu Siang Kung(Va) 


\section{METHODS}

This preliminary acoustic study involves instrumental acoustic analysis and visualization of the vowel formants extracted from a recorded word list that was produced by two Lower Zophei native speakers. The two speakers, a male and female in their early 20s living in central Indiana, are Thomas Thawngza from Tlawngrang and Zai Sung from Lawngtlang. We thank them both for their patience and participation and for sharing their time and knowledge with us. The word list includes correspondences between the two dialects with one token per vowel--two where a single Tlawngrang Zophei (TZ) vowel corresponds with two Lawngtlang Zophei (LZ) vowels--shown in Table 1 . The words in items (1a-j) show similarities in the target vowel where items $(1 \mathrm{k}-\mathrm{x})$ show differences between the two speakers (in bold).

Table 1. Stimuli list

\begin{tabular}{|c|c|c|c|c|c|}
\hline & $\begin{array}{l}\text { Target } \\
\text { Vowel }\end{array}$ & $\mathbf{T Z}$ & $\begin{array}{l}\text { Target } \\
\text { Vowel }\end{array}$ & $\mathbf{L Z}$ & Gloss \\
\hline a. & /ee/ & $\mathrm{p}^{\mathrm{h}}$ éé & /ee/ & $\mathrm{p}^{\mathrm{h}}$ éé & leg \\
\hline b. & /øø/ & lǿǿ & /øø/ & lǿǿ & farm \\
\hline c. & $/ \mathrm{a} /$ & tháytshà & /a/ & thàntshà & worship \\
\hline d. & /i/ & dì & /i/ & dì & correct, return \\
\hline e. & $/ \mathrm{u} /$ & tsáPú & $/ \mathrm{u} /$ & tsáá?ú & book \\
\hline f. & /ay/ & İáy & /ay/ & İáy & root/base \\
\hline g. & /in/ & $\mathrm{t}^{\mathrm{h} i ́ n}$ & /in/ & thín $^{\text {his }}$ & wood \\
\hline h. & /un/ & túy & /uy/ & tún & play (instrument) \\
\hline i. & /on/ & kón & loy/ & kòn & bald \\
\hline j. & /aa/ & Páálùù & /aa/ & Pààlùù & potato \\
\hline k. & $/ \mathbf{i i} /$ & tłì̀ & $/ / \mathbf{i i} /$ & thł̀ & air \\
\hline 1. & $/ \mathbf{u u} /$ & $\mathbf{p}^{\mathrm{h} u ́ u ́}$ & $/ \mathbf{u t} /$ & $\mathbf{p}^{\mathrm{h}} \mathbf{u} \dot{\mathbf{u}}$ & group \\
\hline m. & $/ 00 /$ & póó & $/ \mathbf{a u} /$ & páú & father \\
\hline n. & $/ \mathbf{u} /$ & tù & $/ \mathbf{u t} /$ & tù̀̀ & hoe \\
\hline o. & $/ \mathbf{e} /$ & pè & /i/ & pì & give \\
\hline p. & $/ \mathbf{0} /$ & pahlo & $/ \mathbf{a} /$ & pàhlà & to $\mathrm{mix}$ \\
\hline q. & /ai/ & bàì & /en/ & bén & cheek \\
\hline r. & $/ \mathbf{a u} /$ & páú & $/ \mathbf{u u} /$ & púú & belly \\
\hline s. & /au/ & 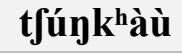 & $/ \mathbf{e} /$ & ts $^{\text {h}} \mathbf{u ̀ \eta k} k^{h} e^{\prime}$ & relative \\
\hline t. & /ei/ & léí & /ii/ & lií & bottom \\
\hline u. & $/ \mathbf{i a} /$ & tláípíá & /ie/ & tléypíé & wall \\
\hline v. & $/ \mathbf{u a} /$ & túá & $/ \mathbf{y o} /$ & týó & do \\
\hline $\mathbf{w}$. & /ue/ & bùèbáá & $/ \mathbf{u i} /$ & bùìbáá & disordered \\
\hline $\mathbf{x}$. & $/ \mathbf{u i} /$ & lúípàà & $/ \mathbf{y y} /$ & lỳỳpà & debt \\
\hline
\end{tabular}

Each token was recorded four times, twice in isolation and twice with a prefixed subject or possessive prefix /a-/ (e.g. túá 'do', à-túá 'he/she did it', phéé 'leg', à-phéé 'his/her leg'), on a head 
mounted Shure SM10A microphone using a Marantz PMD661 MKII solid state recording device. F1 and F2 values were extracted at $20 \%$ and $80 \%$ of the vowel duration automatically using Praat (Boersma \& Weenink 2018) and the script SemiAutoFormantExtractor (McCloy 2012). Vowels were plotted in the charts that follow using the phonR (McCloy 2016) package of R (R Core Team 2014), which also draws an ellipse for each vowel's tokens representing a confidence level according to Hotelling's $\mathrm{T}^{2}$ distribution. Measurements are presented in Bark to facilitate interspeaker comparison.

\section{TLAWNGRANG AND LAWNGTLANG VOWEL SPACES}

\subsection{Basic Vowel Inventories}

Basic vowel inventories for the two speakers included in this study are summarized in Table 2. These data reveal several surface similarities and differences. Bolding is used in Table 2 to indicate vowels which are not present in the vowel system of the other speaker.

Table 2. Overview of $T Z$ and $L Z$ vowel space comparison.

\begin{tabular}{|c|c|}
\hline $\mathbf{T Z}$ & $\mathbf{L Z}$ \\
\hline $\begin{array}{l}\text { - } 6 \text { long monophthongs } \\
\text { /ii, ee, øø, aa, oo, uu/ }\end{array}$ & $\begin{array}{l}\bullet 8 \text { long monophthongs } \\
\text { / ii, yy, ee, øø, aa, uu, iï, } \\
\mathbf{u} /\end{array}$ \\
\hline $\begin{array}{l}\text { - } 5 \text { vowels with length } \\
\text { contrasts } \\
\text { / ii, i, ee, e, aa, a, oo, o, uu, } \\
\text { u/ }\end{array}$ & $\begin{array}{l}\text { - } 4 \text { length contrasts } \\
\text { /ii, i, ee, e, aa, a, uu, u/ }\end{array}$ \\
\hline $\begin{array}{l}\text { - } 7 \text { diphthongs } \\
\quad \text { /ia, ei, ai, au, ui, ue, ua/ }\end{array}$ & $\begin{array}{l}\text { - } 4 \text { diphthongs } \\
\text { /ie, yo, au, ui/ }\end{array}$ \\
\hline
\end{tabular}

TZ and LZ show more similarities in monophthongs than in diphthongs, however surface similarities obscure observations related to lexical correspondences. As shown in Table 1 of the previous section, the data for an individual monophthong or diphthong often comes from a different lexical item. In order to explicate the apparent similarities, Section 4.2 and 4.3 offer overviews of the TZ and LZ vowel spaces, respectively, with both acoustic analysis and phonological schematization. The lexical differences that evince diachronic changes are further discussed in Section 5.

\subsection{Tlawngrang vowel space}

The TZ vowel system 6 long monophthongs, 5 vowels with length contrasts, and 7 diphthongs illustrated in the figures that follow. Figure 2 shows that our TZ language assistant has the following long monophthongs: /ii, ee, øø, aa, oo, uu/. For each token, 8 data points are provided, representing formant values from the 4 recordings of each token and 2 measurements (at $20 \%$ and $80 \%$ of the duration) of each recorded vowel. In this section, color coding is only used for ease of interpretation. 
Indiana Working Papers in South Asian Languages and Cultures

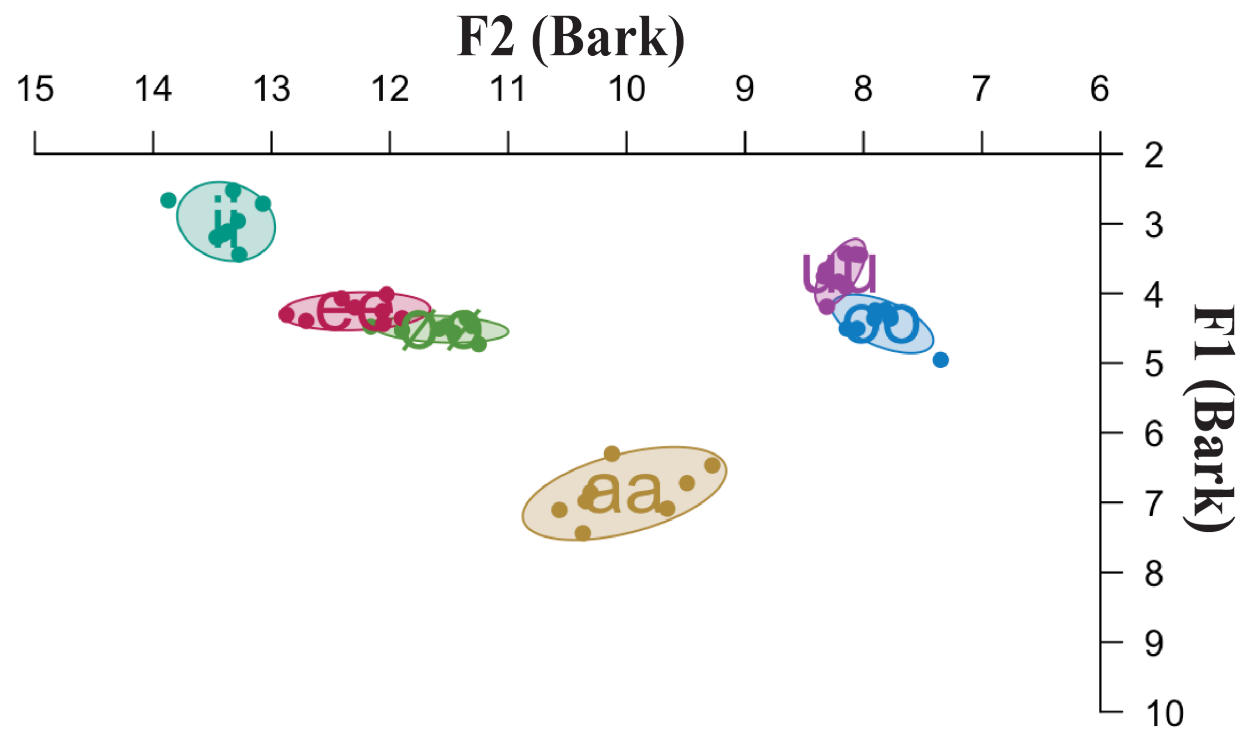

Figure 2. TZ long monophthongs.

Figure 3 shows the 5 long-short length contrasts for this speaker: /ii, i, ee, e, aa, a, oo, o, uu u/. No length contrast has been found for the mid front rounded vowel /øø/. Again here, 8 data points per vowel are provided.

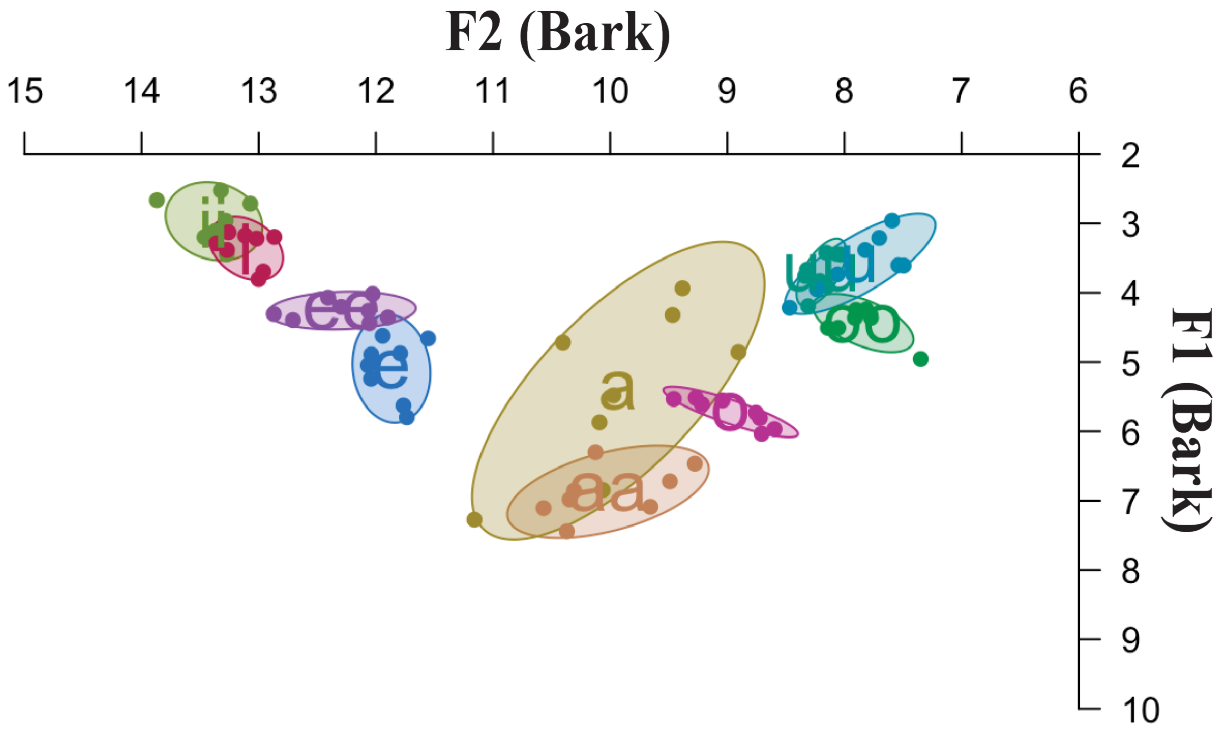

Figure 3. TZ length contrasts.

Figure 4 shows the 7 diphthongs for this speaker: /ia, ei, ai, au, ui, ue, ua/. Here, 20\% and 80\% measurements have been differentiated using filled and empty circles, respectively. 
Indiana Working Papers in South Asian Languages and Cultures

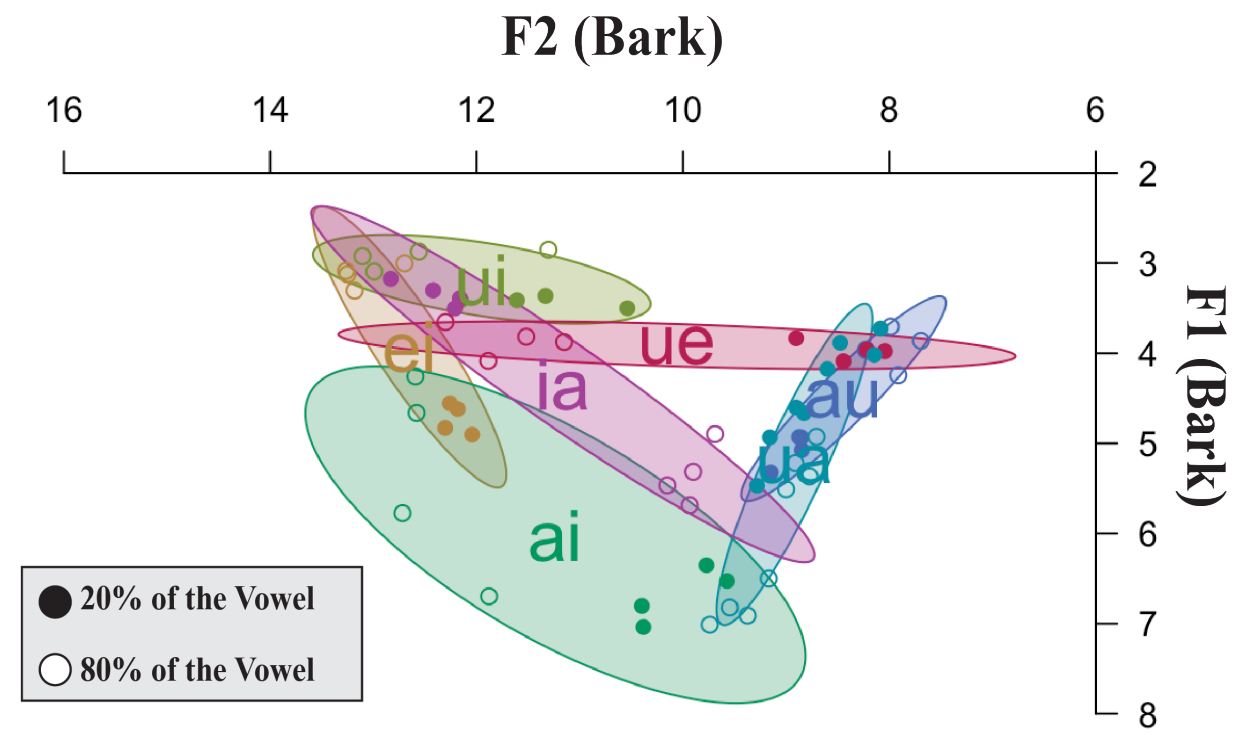

Figure 4. TZ diphthongs.

Figure 5 shows a schematization of the TZ vowel space with long and short monophthongs on the left and diphthongs on the right. Rising diphthongs are given in red, falling diphthongs in blue, and the height harmonic diphthong in green.
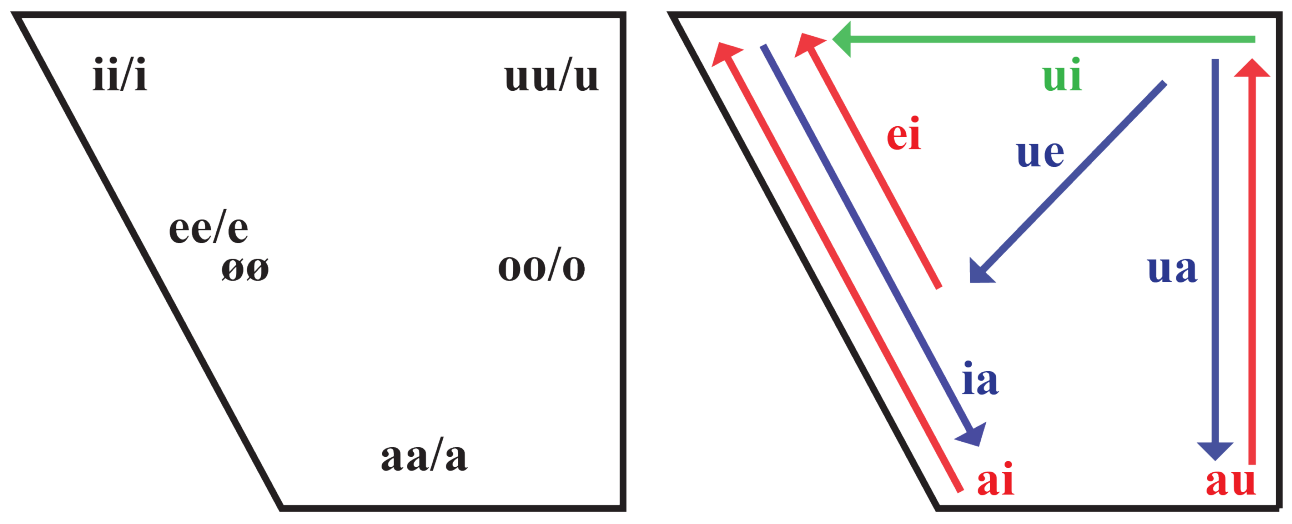

Figure 5. TZ schematized vowel space.

What follows in Section 4.3 is the same information presented in this section but for our LZ language assistant.

\subsection{Lawngtlang vowel space}

The LZ vowel system, unlike the TZ system presented above, has 8 long monophthongs, 4 vowels with length contrasts, and 4 diphthongs, to be shown in Figures 6-9. Figure 6 shows the 8 LZ monophthongs: /ii, yy, ee, øø, aa, uu, ii, $u t /$. The monophthongs /yy, $\ddot{\mathrm{it}}, \mathrm{ut} /$ are analyzed as innovations in section 5. As in the figures in section 4.2, 8 data points are provided for each vowel and color coding is arbitrary and intended only to aid in distinguishing phonemes. It is worth noting here that the high central rounded vowel $/ \mathrm{ut} /$ is produced with frication between the lower lip and upper teeth. 
Indiana Working Papers in South Asian Languages and Cultures

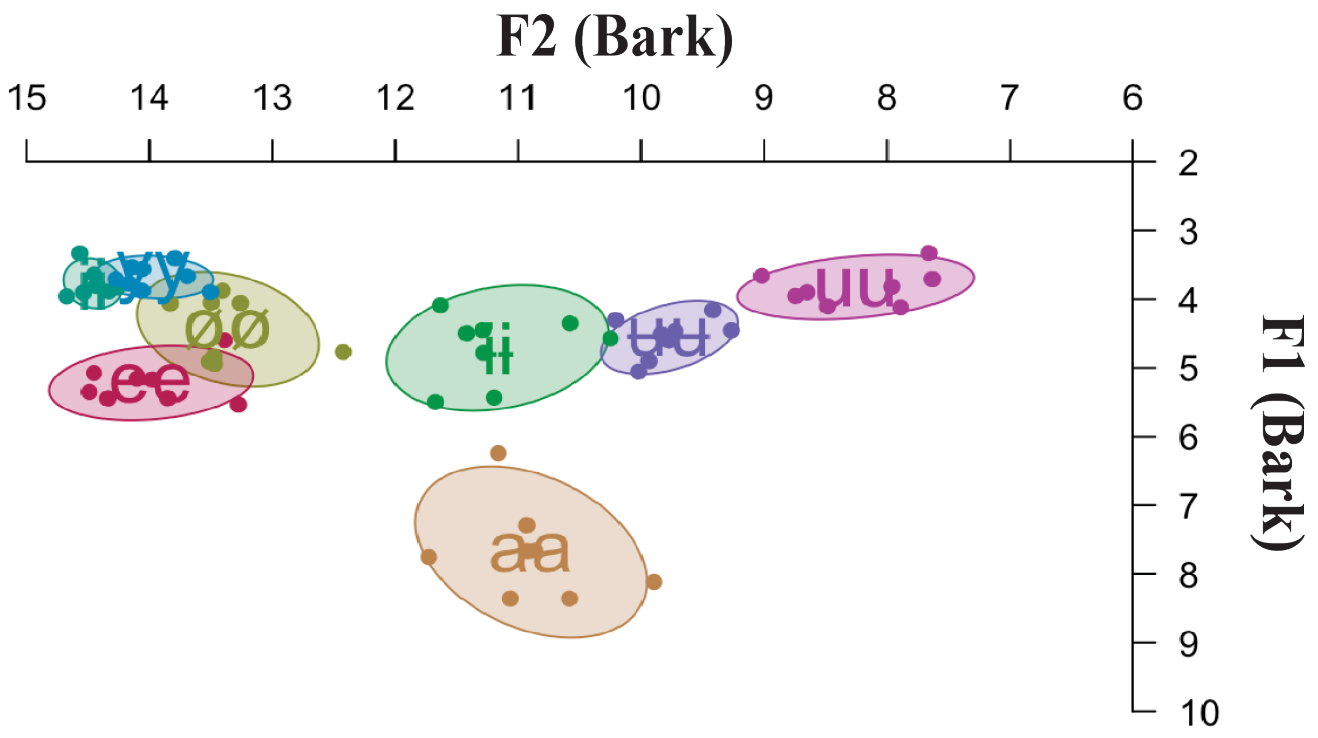

Figure 6. LZ long monophthongs.

Figure 7 shows the 4 length contrasts for this speaker: / ii, i, ee, e, aa, a, uu, u/, missing the /oo, $\mathrm{o} /$ contrast present in TZ. Here no length contrast has been found for the mid front rounded vowel $/ \varnothing \varnothing /$, nor for any of the 3 innovated vowels /ii, yy, $u \mathrm{u} /$, further discussed in section 5.

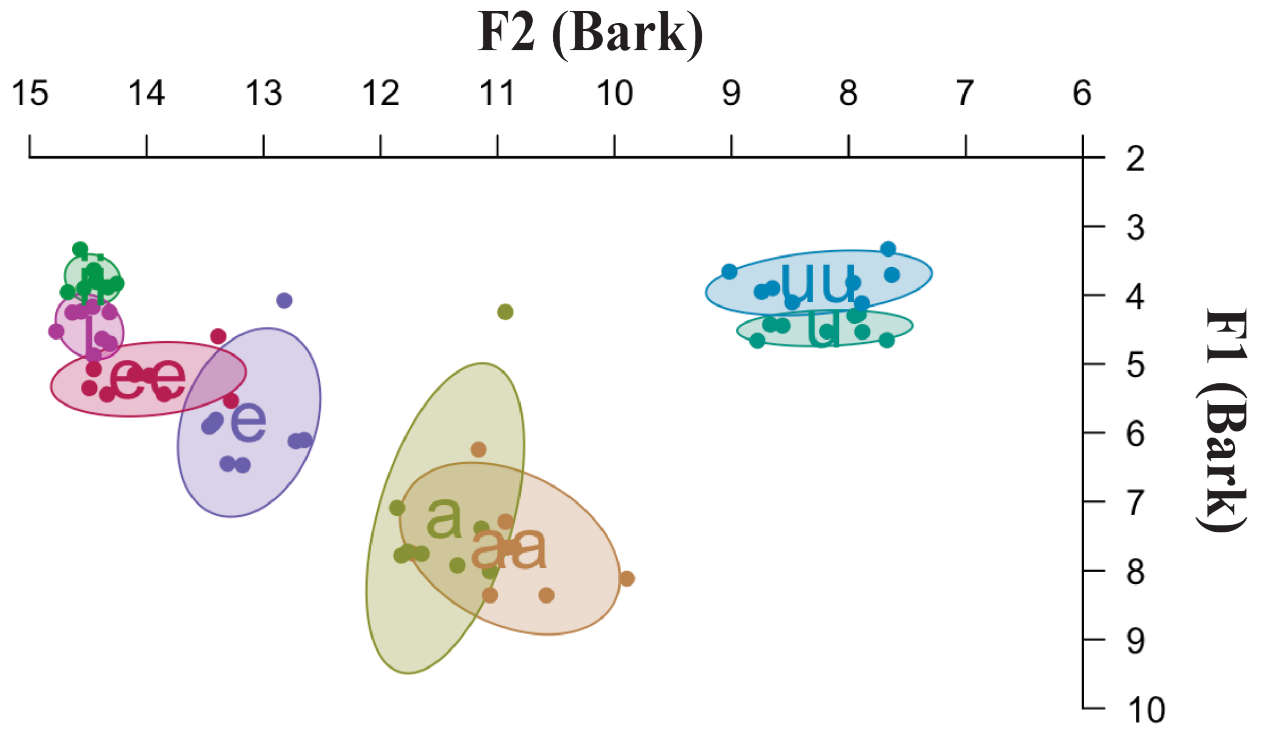

Figure 7. LZ length contrasts.

Figure 8 shows the 4 diphthongs for this speaker: /ie, yo, au, ui/. Here, as in Figure 4, 20\% and $80 \%$ measurements have been differentiated using filled and empty circles, respectively. 
Indiana Working Papers in South Asian Languages and Cultures

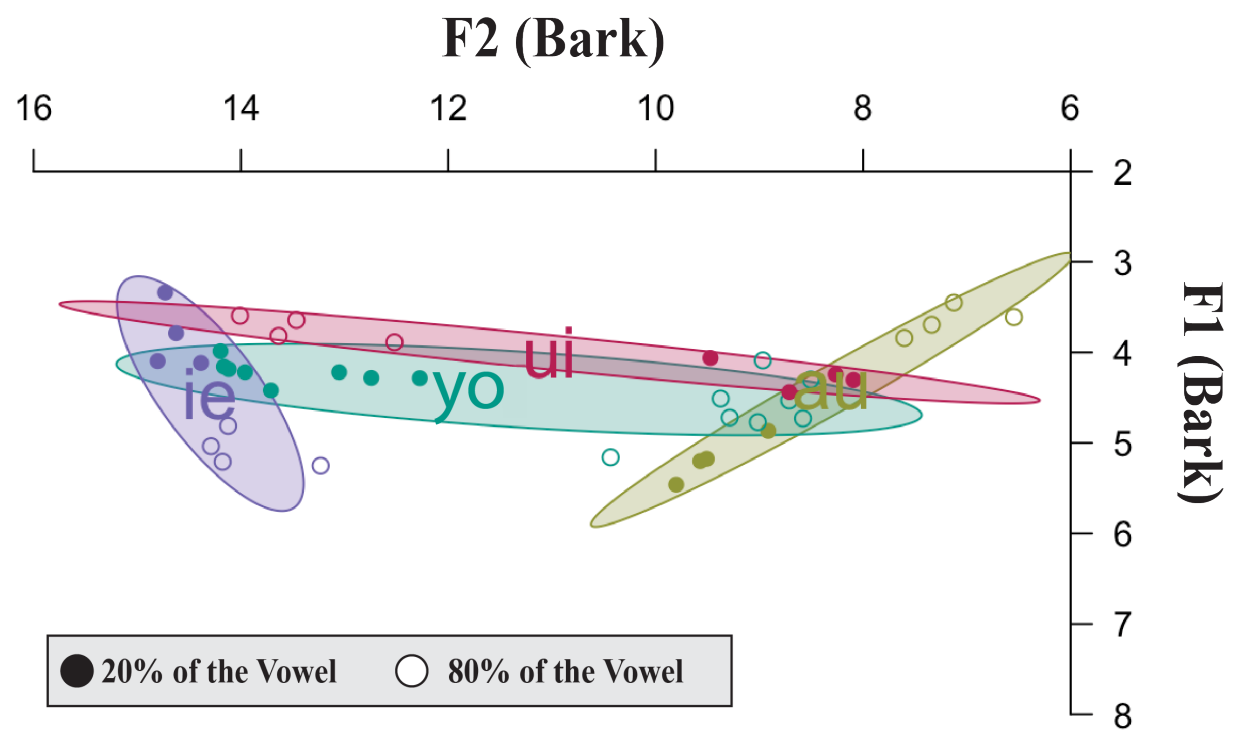

Figure 8. LZ diphthongs.

Figure 9 shows a schematization of the LZ vowel space, including long and short monophthongs (left) and diphthongs (right). As in Figure 5, color coding represents rising diphthongs in red, falling diphthongs in blue, and the height harmonic diphthong in green.
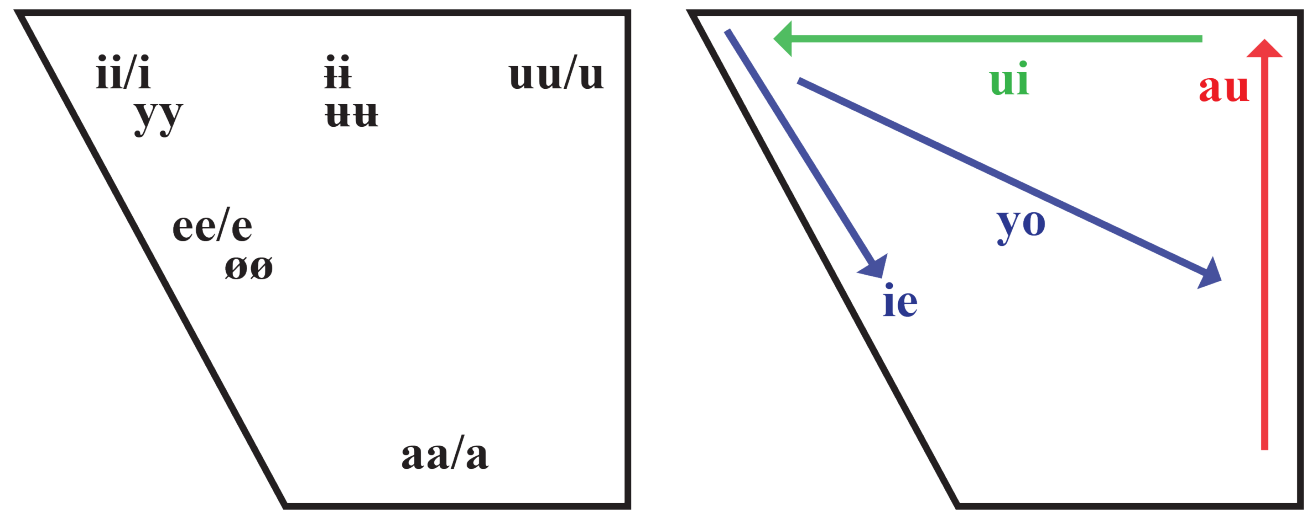

Figure 9. LZ schematized vowel space.

The sketches of these two vowel systems suggest substantial differences in the phonological vowel systems of these two speakers and their respective dialects of Lower Zophei. In Section 5, two series of correspondences, suggestive of diachronic chain shifts in the front and back vowels, are proposed.

\section{PROPOSED DIACHRONIC CHANGES}

\subsection{LZ is likely more innovative}

In pursuing an analysis of the diachronic relationship between TZ and LZ vowel systems, it is useful to identify which dialect is likely more innovative and which is likely more conservative. For reference, the schematized vowel spaces are presented together in Figure 10. 

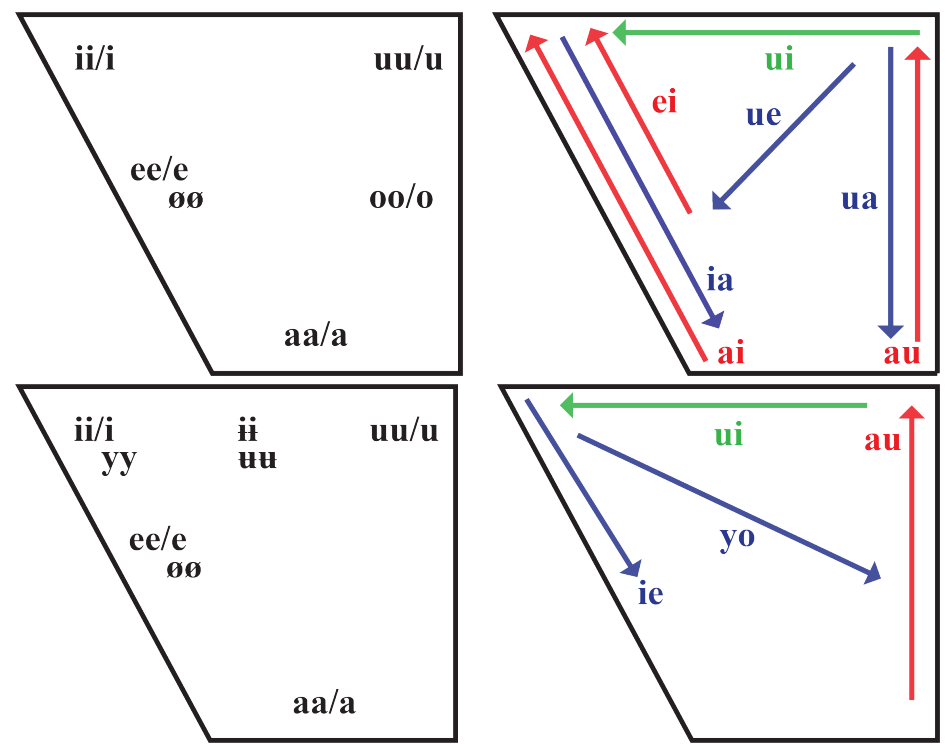

Figure 10. Schematized vowel spaces, monophthongs on the left, diphthongs on the right, TZ above, LZ below.

In this case, it is likely that $\mathrm{TZ}$ is the more conservative dialect and $\mathrm{LZ}$ is more innovative. To motivate this assertion, we turn to the two high central vowels /iit/ and / $\mathrm{tu} /$ and to the other Maraic languages within Kuki-Chin. VanBik (2009) reports the shift from Proto-Kuki-Chin /ii/ to /ii/ occurred in Senthang, but no other Maraic languages, so it is likely an innovation. The presence of $/ \mathrm{ut} /$ in Kuki-Chin has only been attested in the Southern Chin language of Hyow (Zakaria 2017), however preliminary data we have collected from the Maraic language Lautu (also undescribed and bordering the Lower Zophei B-speaking area to the South) shows that it also has the /uu/ to $/ \mathrm{ut} /$ correspondences seen between Lower Zophei varieties. Since $/ \dot{\mathrm{it}} /$ and $/ \mathrm{ut} / \mathrm{are}$ present in LZ and are shared with Senthang and Lautu, respectively, but not common to the Maraic languages, they are likely innovations; so we analyze LZ as the more innovative dialect. Using this analysis as a jumping-off point, we propose two chain shifts, one involving front vowels in Section 5.2 and one involving back vowels in Section 5.3. Both involve the centralization of peripheral vowels (/ii/ and /uu/) and a raising of mid vowels.

\subsection{Front vowel shift}

As justified in the previous section, if we hypothesize that LZ offers the more innovative dialect, the vowel correspondences collected for this study show evidence of a diachronic front vowel shift. This shift involves the centralization of /ii/ (/ii/ $\rightarrow$ /ii $/)$, the monophthongization of /ei/ (/ei/ $\rightarrow$ /ii/), and the raising of /e/ $/(\mathrm{e} / \rightarrow / \mathrm{i} /)$. These changes are shown below in Figures 11-13. Figure 11 shows the more conservative TZ dialect and Figure 12 shows the more innovative LZ dialect. Unlike the arbitrary coloring scheme used in previous figures, matching colors between Figure 11 and Figure 12 indicate lexical correspondences described in Table 3. The monophthong /ee/ is included as a reference despite no indication of change. Figure 13 offers a schematized diagram of this shift. 
Indiana Working Papers in South Asian Languages and Cultures

Table 3. Front vowel shift lexical items.

\begin{tabular}{|c|c|c|c|c|c|}
\hline & Target Vowel & TZ & Target Vowel & LZ & Gloss \\
\hline a. & $/$ ee/ & $\mathrm{p}^{\text {héé }}$ & $/$ ee/ & $\mathrm{p}^{\text {héé }}$ & leg \\
\hline b. & $/$ iii/ & thì̀ & /ìi $/$ & thł̀̀ & air \\
\hline c. & $/ \mathrm{e} /$ & pè & /i/ & pì & give \\
\hline d. & lei/ & léí & /iii/ & líi & bottom \\
\hline
\end{tabular}

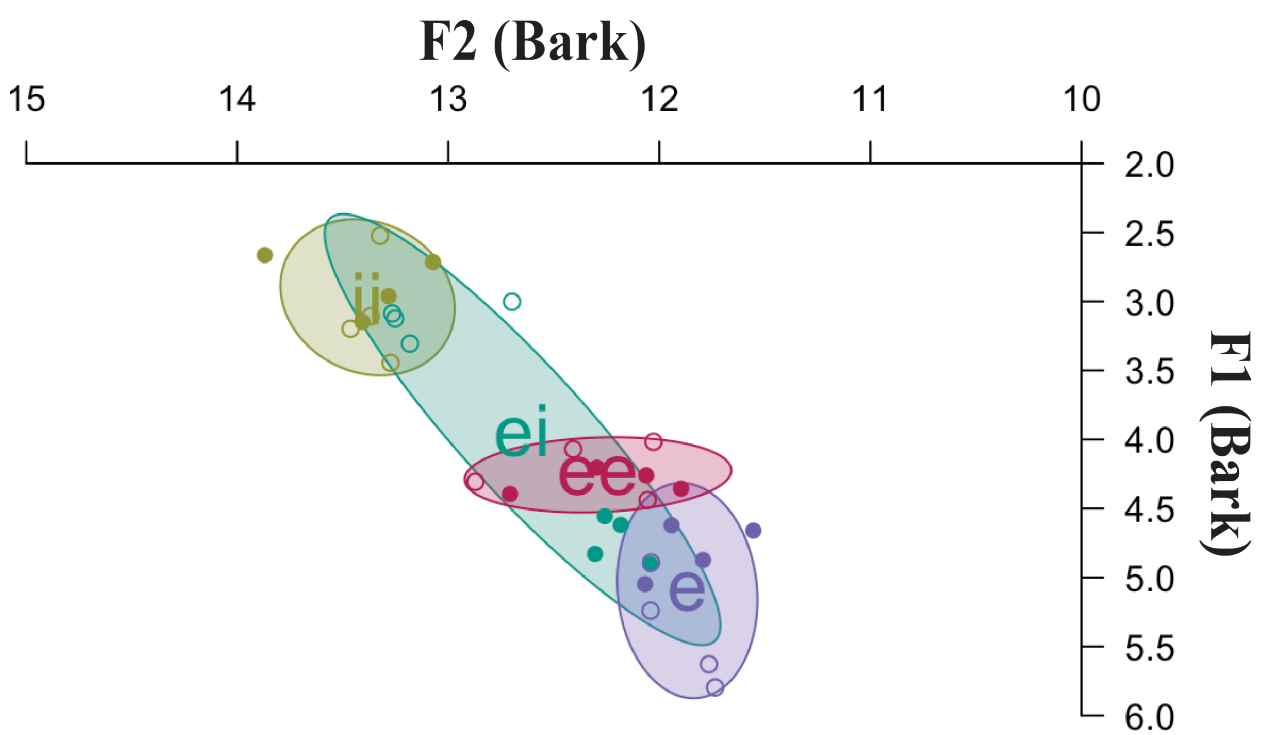

Figure 11. TZ front vowels.

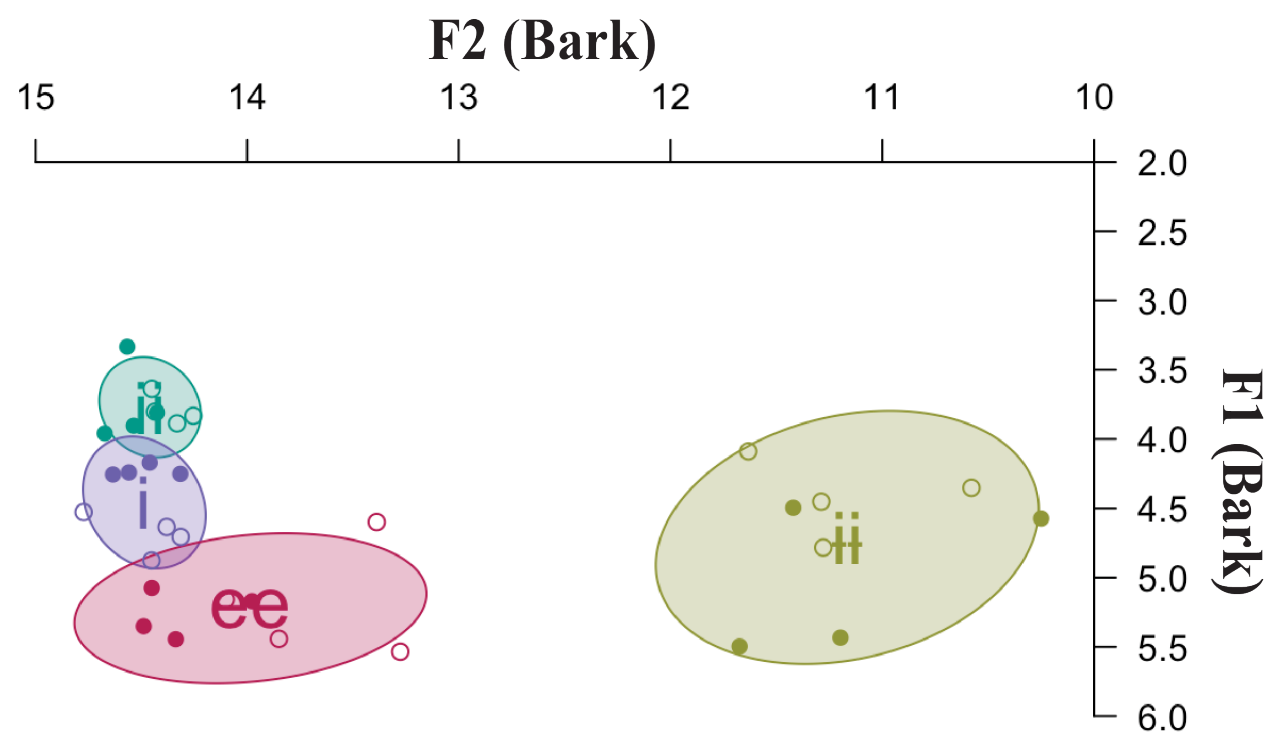

Figure 12. LZ front vowels. 


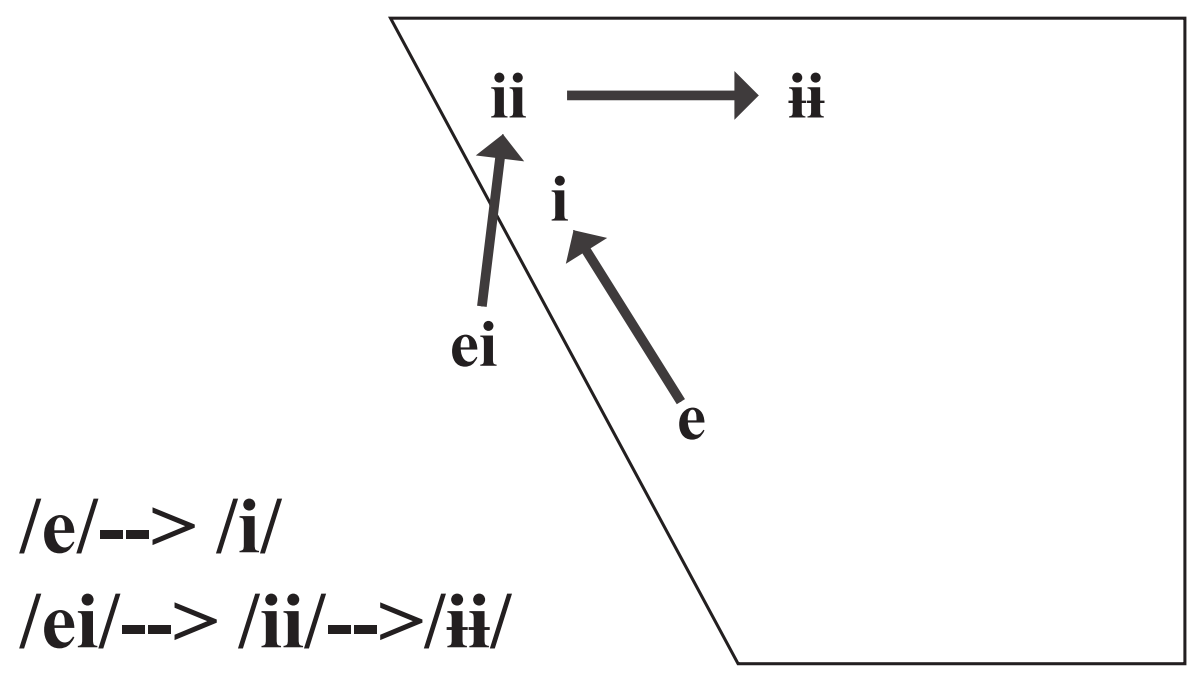

Figure 13. Schematized front vowel shift.

In addition to the shift involving the front vowels, a back vowel shift is also motivated and described in Section 5.3.

\subsection{Back vowel shift}

The back vowel shift posited in this section is more complex than the front vowel shift from the previous section and it shows a similar pattern of peripheral vowel displacement and mid vowel raising. As illustrated in Figures 14-16, this shift involves a centralization of both long and short high back vowels (/uu, u/ $\rightarrow$ /uu/) with a loss of length contrast, monophthongization of /au/ (/au/ $\rightarrow / \mathrm{uu} /$ ), and diphthongization of $/ \mathrm{oo} /(/ \mathrm{oo} / \rightarrow / \mathrm{au} /)$. Also included in these diagrams is the coalescense of /ui/ (/ui/ $\rightarrow$ /yy/), but not included in this diagram (for clarity) is the raising of /ue/ (/ue/ $\rightarrow$ /ui/) shown in (1w). ${ }^{2}$ The back vowels from the more conservative TZ are presented in Figure 14 and from the more innovative LZ in Figure 15. Figure 16 shows a schematization of this shift. As in the previous section, color coding here indicates lexical correspondences given in Table 3.

Table 3. Back vowel shift lexical items.

\begin{tabular}{|c|c|c|c|c|c|}
\hline & Target Vowel & TZ & Target Vowel & LZ & Gloss \\
\hline a. & $/ \mathrm{uu} /$ & $\mathrm{p}^{\text {húú }}$ & $/ \mathrm{uu} /$ & $\mathrm{p}^{\text {h'úú }}$ & group \\
\hline $\mathrm{b}$. & $/ \mathrm{oo} /$ & póó & $/ \mathrm{au} /$ & páú & father \\
\hline c. & $/ \mathrm{u} /$ & tù & $/ \mathrm{uu} /$ & tùù & hoe \\
\hline $\mathrm{d}$. & $/ \mathrm{o} /$ & pahlo & $/ \mathrm{a} /$ & pàhlà & to mix \\
\hline e. & $/ \mathrm{au} /$ & páú & $/ \mathrm{uu} /$ & púú & belly \\
\hline f. & $/ \mathrm{ui} /$ & lúípàà & $/ \mathrm{yy} /$ & lỳỳpà & debt \\
\hline
\end{tabular}

\footnotetext{
${ }^{2}$ In addition, the lexical item that yields /ue/ in LZ and /ui/ in TZ, is the only attested word with this diphthong in either Zophei variety and is thus a likely borrowing from Hakha Chin buai-bai 'very busy, confused, be disordered' (VanBik, personal communication, July 13, 2019)
} 
Indiana Working Papers in South Asian Languages and Cultures

F2 (Bark)

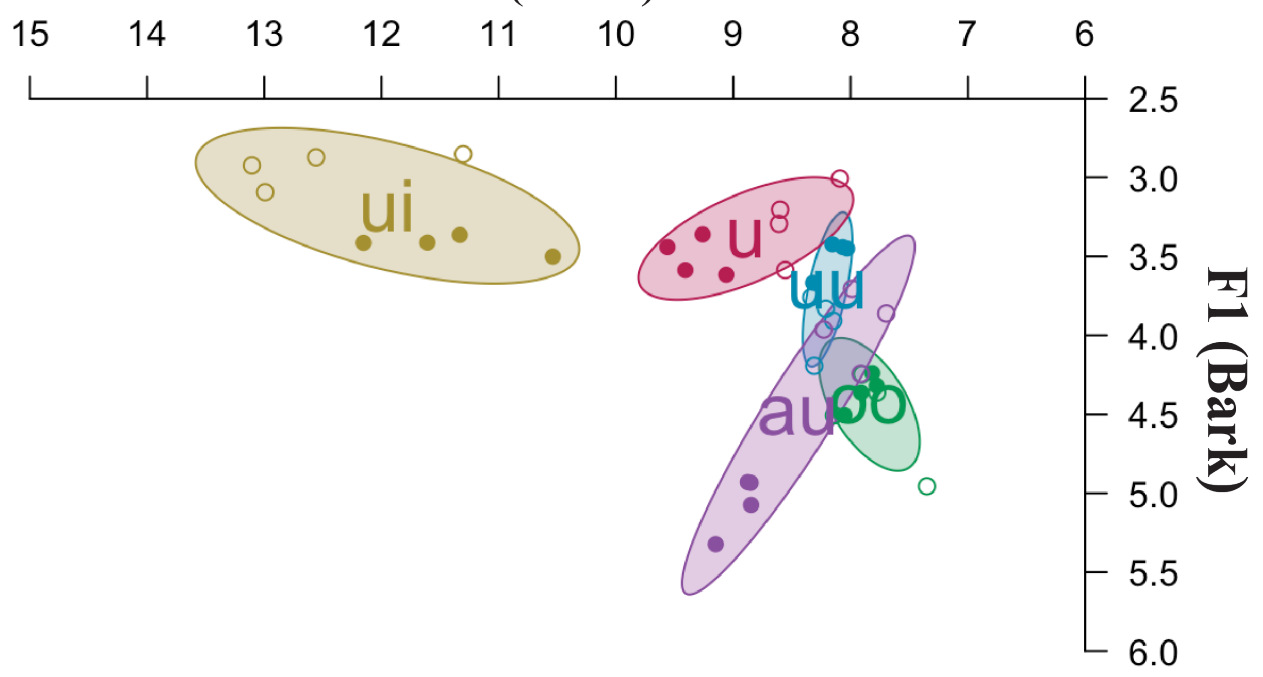

Figure 14. TZ back vowels.

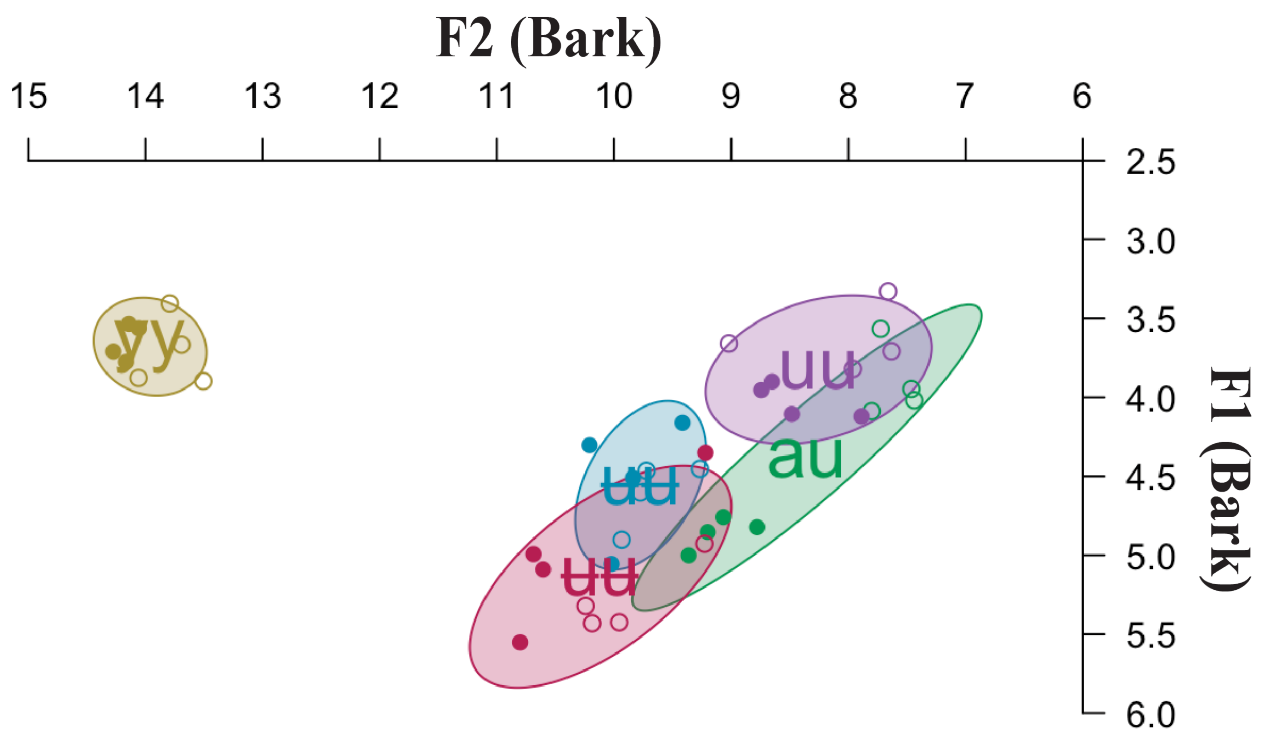

Figure 15. LZ back vowels. 


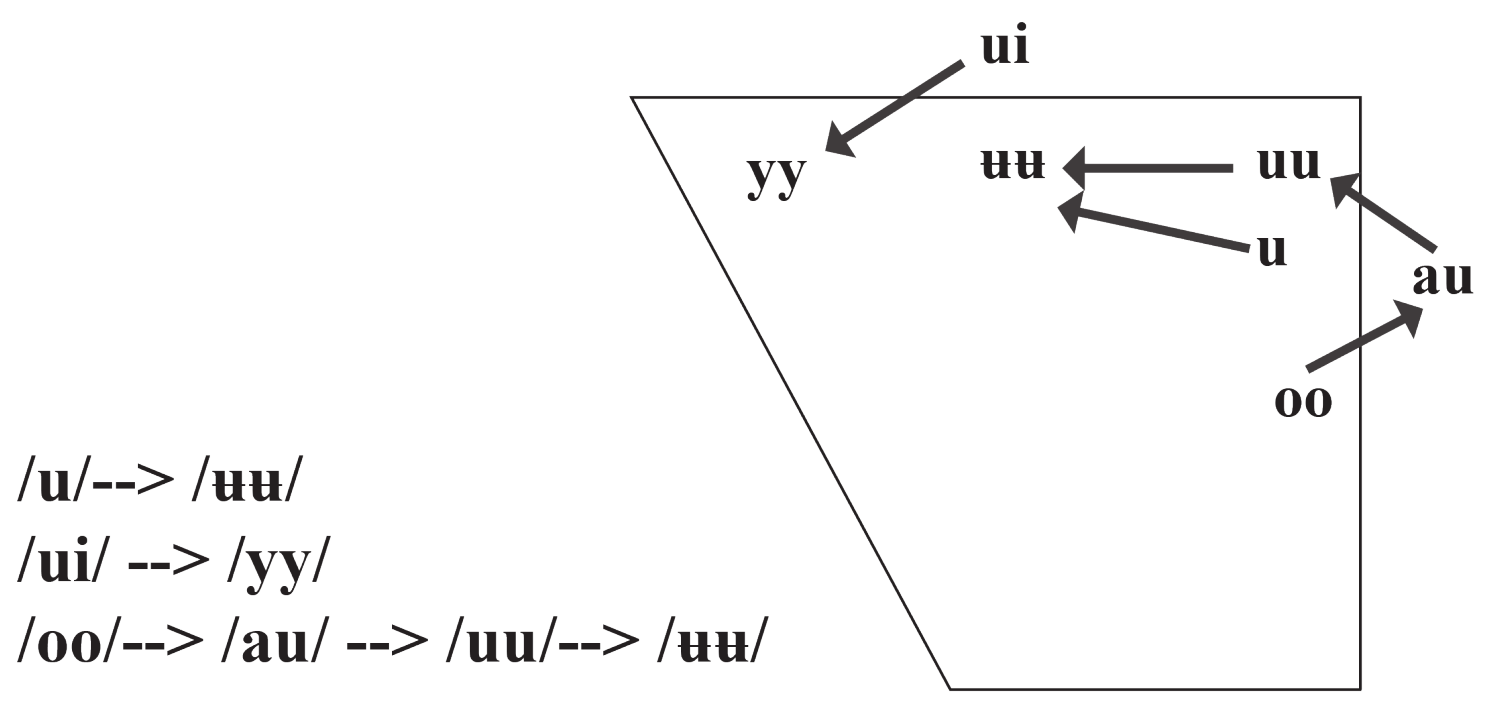

Figure 16. Schematized back vowel shift.

Due to these proposed diachronic changes, many surface similarities in the language can be contextualized. For example, both dialects share the diphthongs /au/ and /ui/ as well as the monopththongs /ii/ and /uu/ but from different lexical sources. A similar back vowel shift has apparently taken place in neighboring Lautu which can be seen in the language name itself. Although the wider Chin community pronounces the language [lautuu], the Lautu language assistant we have consulted refers to the language as [luutut] (and writes it as $<$ Lutuv $>$ ) with audible frication present on the final vowel as in LZ. Though this requires further investigation, if Lautu also displays the /au/ $\rightarrow / \mathrm{uu} /$ and $/ \mathrm{uu} / \rightarrow / \mathrm{uu} / \mathrm{shifts}$, such a change may be an areal feature in the central part of the Maraic-speaking area.

\section{CONCLUSION}

This paper offers the first published data on Zophei, specifically on the vowel systems of two Lower Zophei speakers, one from Tlawngrang and one from Lawngtlang. These systems show many surface similarities which on further investigation contain evidence of a vowel shift involving the centralization of high peripheral vowels /ii/ and /uu/ and the raising of mid vowels. In examining these vowel systems, we hypothesize that LZ is the more innovative dialect and TZ is the more conservative dialect. This analysis is not without problems, for example /en/ in LZ corresponds to /ai/ in TZ where the latter is the likely innovation. VanBik (2009) reconstructs (1q) 'cheek' as *bian in Proto-Kuki-Chin because the nasal coda is shared among many Kuki-Chin languages. Mara (a Maraic language bordering the Lower Zophei-speaking area to the west) shows the reflex bài, similar to the TZ bài, where LZ has the more conservative bé $y$. This change may thus be an areal feature affecting Mara and Lower Zophei A. Additionally, some correspondences such as $\mathrm{TZ} / \mathrm{au} /$ to $\mathrm{LZ} / \mathrm{uu} /$ or /e/ in (1r-s) suggest either outside borrowings or changes differing by phonological context (such as in monosyllabic vs. disyllabic words) has created a 1:2 relationship between some vowels that requires further investigation. Finally, community members consulted report that the Zophei people migrated westward, so it is probable that study of Upper Zophei will help to fill in our knowledge of the diachronic processes involved. In all, more data is needed to test these hypotheses and to paint a more complete picture of the 


\section{Indiana Working Papers in South Asian Languages and Cultures}

relationship between Maraic languages, data from other speakers from the two village dialects investigated here, data from speakers from surrounding villages in the reported Lower Zophei Aand B-speaking areas, data from Upper Zophei, and data from Lautu. With a large population of Kuki-Chin language speakers in Indiana, future research intends to fill these gaps.

\section{REFERENCES}

Boersma, P. and Weenink, D. (2018) Praat: doing phonetics by computer [Computer program]. Version 6.0.43, retrieved 8 September 2018 from http://www.praat.org/

McCloy, D. (2012) SemiAutoFormantExtractor. [Praat Script]. Version 0.3, retrieved 8

September 2018 from https://github.com/drammock/praatsemiauto/blob/master/SemiAutoFormantExtractor.praat

McCloy, D. R. (2016) phonR: tools for phoneticians and phonologists. R package version 1.0-7.

R Core Team (2014) R: A language and environment for statistical computing. R Foundation for Statistical Computing. Vienna, Austria. Retrieved 8 September 2018 from http://www.Rproject.org/.

Simons, G. F. and C. D. Fennig (eds.), (2018) "Ethnologue: Languages of the World, Twentyfirst edition" (SIL International, Dallas, Texas), Online version: http:/www.ethnologue.com.

Vahnie, E. (2018). Executive Director of the Burmese American Community Institute. Personal Communication.

VanBik, K. (2009) Proto-Kuki-Chin: A Reconstructed Ancestor of the Kuki-Chin Languages. STEDT Monograph Series, Vol. 8. (University of California, Berkeley, California)

VanBik, K. (2019, July 13). Email.

Zakaria, M. (2017) "A grammar of Hyow,” Doctoral dissertation, Nanyang Technological University Singapore. 